\title{
Teaching Methods Indications for Education and Training of Sport Skills
}

\author{
Raiola Gaetano1 \\ Tafuri Domenico 1 \\ Lipoma Mario² \\ 1 University Parthenope of Naples, Italy \\ 2University Kore of Enna, Italy
}

\section{Doi:10.5901/mjss.2016.v7n2s1p421}

\begin{abstract}
This work, starting from the theories of the movement, wants to provide applicative methodological guidance on the understanding of the task, the importance of the variability, the revaluation of the error and of the extrinsic feedback. This last certainly one of the most important aspects about the problems of motor control and then learning the technical skills and sports. From these conceptual approaches are derived some important implications, in terms of teaching, from which to draw indications applicative control and learning of technical skills and sports like basketball at school.
\end{abstract}

Keywords: motor control, learnings, feedback, methodology, performance.

\section{Introduction}

The technique is a key determinant of performance, while learning and technic improvement constitute a fundamental objective of training in all sports. The teacher must be able to provide students with information that allows understanding of the task, to plan adequately the lessons aimed at acquiring the technical skills and sports and to identify appropriate strategies for error correction.

Several theories of movement are proposed as models from which to draw information applicative to structure appropriately the teaching of motor skills. Starting from the idea that the motor pattern can be viewed as a generalization of concepts and relationships derived from experiences, allowing you to identify the specifications required to run a particular version of a motor program.

The motor program, considered as an abstract structure in memory that precedes the action and contains the patterns of muscle contractions and relaxations that define the movement (Adams, 1987), therefore the motor program, to start his movement, does not need the feedback produced from the responce, since it contains in memory a set of instructions (which muscles contract it, in what order, how long, ...) are able to initiate the required action. The General Motor program (Schimdt, 2003) are therefore the starting point for the development of motor patterns based on adjusting the feedback. The execution of any movement, and thus also of a sports technique, is never repeated exactly the same way, but adjustments to the motor program must be continuously made it in order to adapt the execution to the requirements environmental. Bernstein (1967) in his studies has created a very unique idea: "to start a movement of the motor system must select a mode of action more appropriate and relevant to the aim from pursued." He called all these possibilities of action of a group of muscles and limbs degrees of freedom, which are considered, screened and selected, to then be put in place. From these conceptual approaches are derived some important implications, in terms of teaching, which providing methodological guidelines applicable to the control and learning of technical skills and sportive. Among the more significant indications are found the methods of information for the understanding of the task, the role of the variability of the practice, the meaning of the error and the utilization of feedback during learning.

\section{Aim}

This work aims to provide applicative methodological guidelines on the understanding of the task, the importance of the variability and availability, the revaluation of the error and the extrinsic feedback in learning technical skills and sportive like basketball at school. 


\section{Methodological Indications and Result}

\subsection{Understanding of the task}

At the beginning of the learning, the student will form in his mind an image inaccurate of the gesture required, then that image will be little by little more precisely and will be enriched by various sensory data (auditory, visual, kinesthetic, tactile, etc ...) at the same time the motor performance improve. A first didactic aspect to consider are the information that the teacher must provide to the student to facilitate the understanding of the motor task and the formation of a mental image progressively more precise and adherent to the ideal model awaited. With young students, early of the learning, they should be given priority, in general, to visual information, which allow us to catch the gesture as a whole, therefore demonstration should be as precise as possible while meeting the speed of actual implementation. Though, the learning could be depend on student's ability for several perception canal: audio, kinesthetic ...

\subsection{Importance of variability}

The greater the variation of the parameters used in the same motor program, the more accurate it becomes the gesture sought. The learning of this motor pattern becomes more effective, efficient and economical as much as is diversified the experience done; therefore, the variability of the practice, understood as the variation of parameters applied to a same motor program, represents an element that contributes to the formation of a pattern more and more precise and accurate (Schmidt,Wrisberg, 2004). Perform a teaching of motor activities of type heuristic, it means helping the student to find possible solutions to a given motor task in a given context, emphasizing the executive variability (Pesce, 2002).

A methodological aspect to consider is that the variable practice is not advantageous for the achievement of immediate objectives, but it becomes to long-term objectives, especially in the sports of situation (basketball, volleyball, soccer, etc ...), which require the adaptation of the technical gesture to changing conditions (Figures 1, 2, 3, 4).
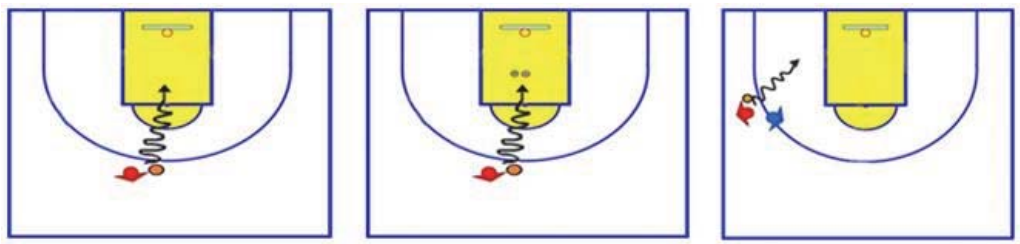

Figure 1. Entrance central in 3th time Figure 2. Entrance central with obstacles Figure 3. Lateral entrance with defender

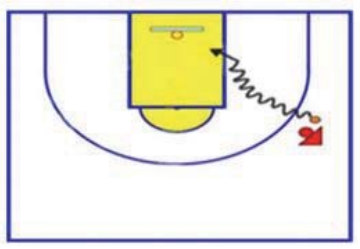

Figure 4. Lateral entrance in 3rd time

\subsection{Revaluation of the error and the extrinsic feedback}

In a specific motor action the student can make two types of errors: in the choice of the response (not appropriate) or in the execution of the movement. In the first case, program selection is inappropriate due to an incorrect assessment of the environmental conditions, for example, in basketball, a wrong assessment of the trajectory of the ball leads to a placing defensive which, although carried out correctly from the point of view of technical and tactical, It is not appropriate to the situation (fig. 5). In this case, the chosen program is incorrect because, although well made, is ineffective to achieve the goal. 


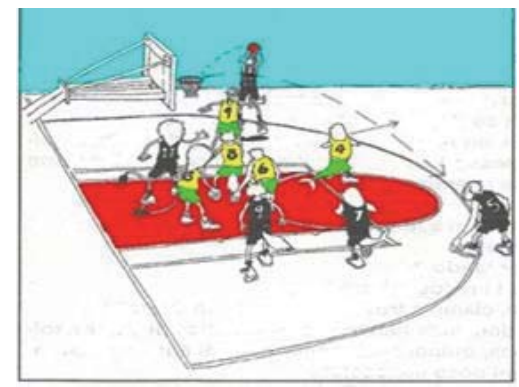

\section{Figure 5. Position wrong}

In a program chosen correctly can be instead an error during the execution due to an inadequate control of the movement. When a beginner has not mastered a motor gesture, or when an experienced player can not control an automated movement, because of emotional factors related to the performance or simply to fatigue, a motor program correctly chosen not is perfectly realized. The two types of error, however, can occur simultaneously. In the sport of situation, like basketball, the purpose of the feints is precisely to induce the opponent at start a motor program inappropriate, because the change takes more time.

An important aspect of the didactic relates to the information that the teacher must provide the student after the execution of a technical gesture, for to correct any errors or repeat the correct movement in subsequent tests (Parisi, Raiola, 2014ab). This information on the result of the performance deriving from external sources at subject are the extrinsic feedback additional, such information may be provided in the form quantitative or objective, or in qualitative form relatively to the way you ran the movement. Is necessary always evaluate the dual function of feedback (information and reinforcement) and determine appropriate instructions that have a negative value with those who have a positive meaning, bearing in mind that messages you send to students may also be of nature non verbal (Mantovani, 2004).

In the process of learning / teaching this information subsequent to performance are a variable easily manipulated by the teacher, but with a different meaning depending on the age and abilities of the students. For example, the frequency of the corrective action must be greater in the early stages of learning; After is appropriate to reduce the frequency of extrinsic feedback to the advantage of that intrinsic. The extrinsic feedback contributes to the elaboration of the reference of correctness with which compare the intrinsic feedback during execution, so is useful for the formation and for the strengthening of motor pattern.

\section{Discussion}

Learn and refine new and always different technical gestures (sport skills) should to be choose in relation to a specific coordinative capability from develop, such as the change of direction, the shooting feint, the change of direction, etc.. And good rule to remember that the highest level of coordination is one in which the student, in addition to successfully perform the gesture, keeps active the possibility to modify it and adapt it to the "situation" while maintaining the effectiveness (Raiola et al, 2016ab, Raiola, 2015ab, Raiola et al., 2015, Gaetano et al, 2015ab, Altavilla et al, 2014, Gaetano, Rago 2014, Raiola, Tafuri 2015ab).

To be adept, moreover, involve be sure of the own abilities and improve the efficiency of an skill is reflected in an increase in security, the reduction of energy consumption and, sometimes, the reduction of time in the execution of a movement . This means reducing or eliminating unintended movements and unnecessary. A learning, however, only learned a abstract cognitive level stays away from the real context and from the direct experience (Altavilla, Raiola, 2014). Ultimately, be especially skilled in any field, and specifically in the performance of motor tasks, implies sharpen and train baggage of the motor skills that you possess. A failure and continuous solicitation, even in the presence of considerable capability, will never render skilled or capable of learning new motor tasks. This objective is accomplished through a long period of work, through numerous exercises performed with conscious control and with a great variety of motor experiences. The success of our teaching comes from our ability to pass on to young people the right information techniques, tactics and the mindset of working for the improvement of individual and personal growth (Gaetano, 2012ab, Altavilla, Raiola G., 2015, Altavilla et al, 2015ab). 


\section{Conclusions}

This article is intended as an example of how to apply different methodological indications that any teacher can use in support of the proposed exercises, taking into account the level of motor development of its students and of the exercises proposed, in which every student can experiment with new technical gestures effectively and economic, thus increasing their technical and tactical skills and thus improving the performance. It goes without saying that during the process of training must be clear the aims, instructions precise for the exercises, the feedbacks must be always appropriate and motivating in order to get an effective workout and with the active participation and aware by all students.

\section{References}

Adams J.A., 1987, Historical review and appraisal of research on the learning, retention, and transfer of human motor skills Psychological Bulletin,

Altavilla G., Raiola G., 2015, Sports game tactic in basketball, Sport Science 81

Altavilla G, Furino F, Di Palmo M, Raiola G, 2015a, Physical skills, sport learning and socio-affective education Sport Science, 81 supplement

Altavilla G, Furino F, Di Palmo M, Raiola G, 2015b, The child hypokinetic and the overtrained Sport Science, 81 supplement

Altavilla G., Tafuri D., Raiola G., 2014, Some aspects on teaching and learning by physical activity, Sport Science, vol 8 issue 2,

Altavilla G., Raiola G., 2014, Global vision to understand the game situations in modern basketball, Journal of Physical Education and Sport

Bernstein N.A., The Coordination and Regulation of Movement, London Pergamon Press, 1967

Gaetano R., Domenico T., Gaetano A., 2015a, Physical activity and its relation to body and ludic expression in childhood Mediterranean Journal of Social Sciences Vol. 6, № 3

Gaetano R., Gomez F.P., Gaetano A., 2015b, Anxiety In The Youth Physical And Sport Activity, Mediterranean Journal of Social Sciences Vol. 6, No 3

Gaetano R., Rago, V., 2014, Preliminary study on effects of hiit-high intensity intermittent training in youth soccer players Journal of Physical Education and Sport vol 142 148-150

Gaetano, R. 2012a Didactics of volleyball into the educate program for coaches/trainers/technicians of Italian Federation of Volleyball (FIPAV) Journal of Physical Education and Sport vol. 122 25-29

Gaetano, R. 2012b Motor learning and didactics into physical education and sport documents in middle school-first cycle of education in Italy Journal of Physical Education and Sport vol. 122 157-163

Magill R.A., Motor learning: concept and applications (6th ed.). Dubuque, IA, Brown \& Benchmark, 2001

Mantovani C., Feedback and motor control - Italian Journal of Sports Sciences, Vol. 11 - Number 1-2 2004

Parisi F, Raiola G 2014a, Video analysis in youth volleyball team Journal of Human Sport and Exercise vol 91 584-587

Parisi F, Raiola G., 2014b, The serve in under 12-13 Italian volleyball team Journal of Human Sport and Exercise vol 91 588-591

Pesce C., 2002, Prescriptive teaching or learning heuristic?, SDS Magazine of Culture Sport, 55

Raiola G., Altavilla G., Tafuri D, Lipoma M, 2016a, Analysis of learning of shot in basketball, Journal of physical education, vol. 51

Raiola G, Altavilla G, Di Tore P A, 2016b, Analysis on some aspects of the service in volleyball, Sport Science, 91

Raiola G., 2015a, Basketball feint and non-verbal communication: empirical framework Journal of Human Sport and Exercise vol 101 supplement

Raiola G., 2015b, Sport skills and mental health, Journal of Human Sport and Exercise vol 101 supplement

Raiola G, Tafuri D., 2015a, Teaching method of physical education and sports by prescriptive or heuristic learning. Journal of Human Sport and Exercise vol 101 supplement

Raiola G., Tafuri D., 2015b, Assestment and periodization in amateur soccer team, Sport science, vol 8 supplement 2

Raiola G., Lipoma M., Tafuri D., 2015, Postural control in young soccer players: differences between the cognitive approach and ecological-dynamic one, Journal of Human Sport and Exercise vol 101 supplement

Schmidt, R.A., 2003, Motor Schema Theory after 27 Years: Reflections and Implications for a New Theory, Research Quarterly for Exercise and Sport Volume 744

Schmidt, R.A., Wrisberg, C.A., 2004, Motor learning and performance (3rd ed.) Champaign, IL, Human Kinetics, 